\title{
Creating a knowledge-sharing community
}

\section{The use and expansion of knowledge management at Tulsa Community College}

$\mathbf{K}$ nowledge management (KM) is a very nebulous term. Research on the use of $\mathrm{KM}$ across different types of organizations and disciplines confirms this. This article examines the path that Tulsa Community College (TCC) took to not only build the use of KM across the college, but also to create the support structure to foster the creation of a knowledge sharing community.

In order for an institution to be able to use KM effectively, several questions should be asked. Is there a culture of knowledge sharing at the institution? Is the concept of KM supported by those in the administration?

In the case of TCC, the answers to these questions showed that there were a number of factors that precipitated the use of KM. First, the college began a complete reorganization of its academic units because, as a multicampus community college system, the academic units had become self-contained. A reorganization was carried out that greatly benefited the institution and brought it more in line with a "One College" model.

Secondly, while preparing for an accreditation visit from the Higher Learning Commission, TCC wanted to create a tool that increased transparency and efficiency in the use of organizational knowledge.

Lastly, TCC administrators realized that there were a large number of meetings occurring across the college that did not have a clear mandate. This was the reason for the creation of a council and committee structure at TCC.

The TCC Library realized early in the reorganization process that it was best suited to create a framework and culture for knowledge sharing that would not only benefit the college, but also the library. To begin this process, a knowledge management librarian position was created in 2014. The main duties of this job included KM, records management, and archiving for the college. The initial plan was for the person in this position to manage the organizational knowledge of the four campus libraries and then move this work across the college.

Once a librarian was hired for the position, a plan for pursuing KM was created and submitted to the Library Management Team. The plan was approved, and the process of structuring the organizational knowledge of four campus libraries began. Additionally, several TCC employees attended an intensive training by KM guru Charles A. Tryon Jr. at the TCC Northeast campus in summer 2015. This training provided the foundation for building a knowledge-sharing culture at TCC.

Andy K. Taylor is knowledge management librarian at Tulsa Community College's Northeast Campus Library, email: andy.taylor@tulsacc.edu

(c) 2019 Andy K. Taylor 


\section{Knowledge capture}

Anyone who studies KM understands the value of both tacit and implicit knowledge. It is easy to record implicit knowledge as it already exists, but the TCC library discovered that it would be more difficult to find a way to extract the tacit knowledge of the library employees. In order to do this, a questionnaire was created that would allow the KM librarian to capture that information. Additionally, the KM librarian felt that it was important to meet with as many library employees as possible face-to-face setting. This created a more conversational atmosphere that allowed the TCC library employees to explain the more tacit nature of their job duties. The questionnaire covered areas such as:

- paperwork and documentation,

- complete list of job duties (both official and unofficial),

- discussion of knowledge transfer (How can we transfer your knowledge to others?),

- description of resources used in different levels of the organization, and

- technology specializations.

In order for this "interview" to work in a way that allowed the KM librarian to gather more tacit knowledge from the library employees, there were a number of other questions that were included, such as:

- What do you enjoy most about your job?

- In your opinion, how could the TCC library become more consistent and efficient?

- How do you feel that the knowledge that you possess could be passed on to others?

\section{Choosing a repository product}

Approximately 35 of these interviews were conducted in spring 2015. Once the information was gathered, a review was conducted of all responses in order to ascertain the KM needs of the TCC library. At the time, the library made the decision to use a Springshare LibGuide as a knowledge repository. This platform allowed us to organize the knowledge gained into a structure that was both informative and easy to use. It was also a cost-efficient choice for us, as we were already using the LibGuides platform. This choice worked well for the library because it needed a place to store all of the knowledge that it creates. For example, the TCC library has approximately 11 different teams and working groups that needed a place to store their meeting minutes and agendas. By creating a Library Teams and Work Group Landing Pages folder in the repository, those groups now had a place to permanently preserve all of that information. ${ }^{1}$

\section{Knowledge transfer}

One of the most important aspects of KM is the ability to not only capture information, but also make it easy to access and use. It was during the aforementioned interviews with library staff that this part of the KM process became apparent. There were two specific instances that allowed the library to capture knowledge that had not been documented before.

First, a library employee mentioned that it would be nice to have a section of the guide that lists the technical expertise of all library employees. That information was collected during the interviews, and a page of the KM Guide was dedicated to the transfer of that knowledge. The 20 main areas of technology used in the library were identified, and the area that was created listed each type of technology combined with the contact information of those library employees who had knowledge of or expertise in that area.

Additionally, it was discovered that there were knowledge assets in the library that were known to only a few employees. For example, there were very few library employees who understood how to return books to Amazon if an incorrect order was received. Making this type of knowledge accessible and transferable was helpful to the library staff who were involved with collection development.

One of the most important tenants of $\mathrm{KM}$ is the sharing of knowledge. This is the reason that the TCC Library KM Guide was created in a way that allowed all library employees to be editors. Most all employees 
of the TCC Library serve on one or multiple teams or work groups, regardless of their position within the organization. Making all TCC library employees editors gave everyone the ability to share knowledge. For example, the library has created a revolving schedule for who will take minutes at certain meetings, and this allowed each individual the ability to upload information to the guide.

Additionally, the use of the TCC Library KM Guide by all library employees increased transparency across the organization. All library employees have access to every area of the guide, and this allows every person in the organization access to the same information.

\section{Moving forward}

From the beginning of this project, the TCC library knew that it wanted to eventually use SharePoint as a knowledge repository tool for not only the library, but also for the college. As mentioned before, the college had recently undergone a reorganization that allowed for the creation of a council and committee structure. This structure lent itself perfectly to the creation of a new council and committee SharePoint site for the college. Each council had an area of the site in which to store documents, such as membership lists, agendas, charters, minutes, and templates. Each council then had a corresponding list of committees that re-

\section{KM Guide usage}

Using Lib-

Guides as a

repository

tool plat-

form gave

the library

the ability

to track us-

age of the

guide. The

LibGuides

platform

contains
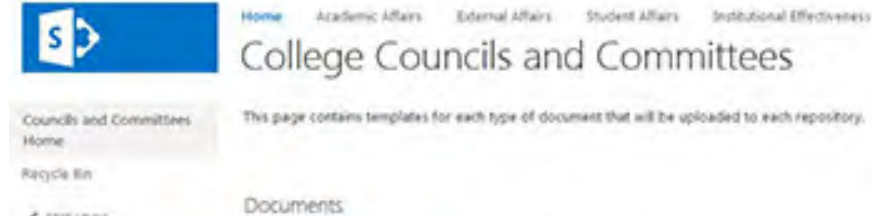

con uss

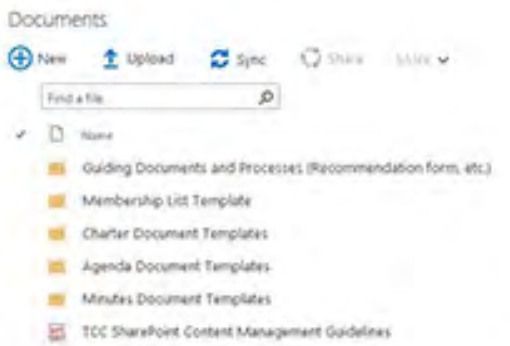

Tulsa Community College Council and Committee SharePoint Site. ported to it.

These "sub-

folders" also

contained

the same

file struc-

ture, thus

allowing the

committees

to store the

same type

of infor-

mation. A

select few

were given

editor rights, feature that allows you to look at usage of your guides over time. For the KM Guide, statistics showed that since the time the guide launched in July 2015, it had been used a total of 7,738 times.

It has been very interesting to see the different ways that library employees use the KM Guide. One of the most important uses of the guide has been as a place to store meeting minutes and meeting agendas. Prior to the creation of the guide, these documents were stored in a variety of different places and on different campuses. This made the review of past minutes extremely difficult. Now we have one centralized location that allows everyone to know what is going on in other areas of the organization. but all employees of the college were given view rights. Much like the library, this structure allowed for a higher level of transparency across the college.

This work also could not have been completed without the tireless work of the TCC cataloging and metadata librarian. This librarian's work was invaluable as elements of the project became clearer (such as structure, naming conventions, etc.). With the two working together, the TCC Council and Committee SharePoint site was successfully launched in late 2017.

Soon after the launch of the Council and Committee site, it became apparent that the college needed a tool that would allow employees across the college to work collabora- 
tively without an account being tied to one employee's email (such as with Dropbox and Google Drive). Working together again, the KM librarian and the cataloging and metadata librarian were able to create a "sandbox" in SharePoint that allowed groups that requested a collaborative space to work. This new area is called the TCC Collaborative Workspace. Training documents have been developed, and, to this point, four groups have requested collaborative sites. This site will continue to grow, and trainings across the college will

be offered in the near future.

\section{Lessons learned}

Now that different areas of TCC have started using SharePoint, it is time to put the lessons learned to work for us in the TCC library. We have now transitioned from the TCC Library KM Guide to the TCC Library Knowledge
Management SharePoint site. The structure of the original LibGuide translates perfectly into the structure of a SharePoint site, and having this site gives us the opportunity to build the site using all of the lessons we have learned from building SharePoint sites for other parts of the college.

Moving forward, we plan on using our site as a model to show other areas of the college what we can build for them. We have been given positive feedback on the SharePoint sites that we have built up to this point, and we plan on continuing our work in $\mathrm{KM}$ to create a true knowledge sharing community at TCC.

\section{Note}

1. You can view the TCC Library Knowledge Management LibGuide by visiting https://guides.library.tulsacc.edu/TCCKM. $>2$

("Reimagining the research assignment," continues from page 17)

2017, http://libguides.library.ohiou.edu /imagine.

6. "Reimagining the Research Project: a Faculty-Librarian Collaborative Project at Ohio University," Ohio University, accessed December 19, 2017, https://youtu. be/gJwIlvv8lqY.

7. Paul C. Campbell and Miriam Intrator, "Making First Contact with Primary Sources: How Collaborating with Faculty and Library Special Collections Increases Student Engagement in Teaching IL" (presentation, LOEX 2018, Houston, Texas, May 3-5, 2018).

8. Paul C. Campbell and Miriam Intrator, "Collaboration with Faculty and Library
Special Collections: Increasing Student Engagement with Primary Sources" (poster, Conference of California Academic and Research Libraries, Redwood City, California, April 13-15, 2018).

9. Hanna Schmillen, Jeffery A. Russell, and Sherri Saines, "Reimagining a Research Assignment in Performing Arts Medicine: Librarian-Faculty Collaboration to Increase Information Literacy Skills and Student Success" (poster, Medical Library Association Annual Meeting, Seattle, Washington, May 27-31, 2017).

10. Open Textbook Network, http:// research.cehd.umn.edu/otn/about-us/. $\boldsymbol{z}$ 